\title{
The feelings and thoughts of mental health nurses concerning the management of distressed and disturbed in-patients: A comparative qualitative European study*
}

\author{
Vida Staniulienè ${ }^{1}$, Mary Chambers ${ }^{2 \#}$, Xenya Kantaris ${ }^{2}$, Raija Kontio ${ }^{3}$, Lauri Kuosmanen ${ }^{4}$, Anne Scott $^{5}$, \\ Maria Antónia Rebelo Botelho ${ }^{6}$, Renzo Zanotti ${ }^{7}$, Maritta Välimäki ${ }^{8}$ \\ ${ }^{1}$ Faculty of Health Sciences, Klaipeda State College, Klaipeda, Lithuania \\ ${ }^{2}$ Faculty of Health, Social Care and Education, Kingston University and St. George's, University of London, London, UK \\ ${ }^{3}$ Department of Nursing Science, University of Turku and Hospital District of Helsinki and Uusimaa, Tuusula, Finland \\ ${ }^{4}$ Department of Nursing Science, University of Turku, Turku, Finland \\ ${ }^{5}$ Dublin City University, Dublin, Ireland \\ ${ }^{6}$ Nursing Research and Development Unit, Escola Superior de Enfermagem de Lisboa, Coimbra, Portugal \\ ${ }^{7}$ Department of Molecular Medicine, University of Padova, Padua, Italy \\ ${ }^{8}$ Department of Nursing Science, University of Turku and Hospital District of Southwest Finland, Turku, Finland \\ Email: ${ }^{*}$ M.Chambers@kingston.sgul.ac.uk
}

Received 21 August 2013; revised 22 September 2013; accepted 19 September 2013

Copyright (C) 2013 Vida Staniulienè et al. This is an open access article distributed under the Creative Commons Attribution License, which permits unrestricted use, distribution, and reproduction in any medium, provided the original work is properly cited.

\begin{abstract}
High levels of distress and disturbance amongst those experiencing acute mental illness can be a major problem for mental health nurses. The feelings experienced by these nurses when caring for and supporting disturbed and/or distressed patients along with their concurrent thoughts are not well described in the literature. To date, this complex issue has not been explored within a comparative European context. The objective of this qualitative study was to explore the feelings and thoughts of mental health nurses when supporting and caring for distressed and/or disturbed patients in 6 European countries. Methods: Focus groups were used to collect data from 130 mental health nurses working in acute inpatient psychiatric settings. Results: Data were analysed using content analysis. Findings highlighted 6 broad themes: 1) Mixed emotions: expressive and responsive, 2) Procedure for caring for and supporting disturbed and/or distressed patients, 3) Use of guidelines for caring and supporting disturbed and/or distressed patients, 4) Team and organisational support, 5) Ethical concerns: Cognitive dissonance and 6) Education and training. Commonalities and differences were

*Funding: This project has been funded with support from the European Commission's Leonardo da Vinci programme (2006 FI-06-B-FPP-160701). This article reflects the views of the authors only, and the Commission cannot be held responsible for any use of the information contained herein.

${ }^{\#}$ Corresponding author.
\end{abstract}

found across all themes. Approaches to care, nurses' role and education, clinical guidelines and/or standards vary from country to country, therefore the care, treatment and management of distressed and/or disturbed patients are various. As a result, mental health nurses have different experiences, various emotional quandaries concurrent with cognitive dissonance and different coping strategies when caring for and supporting distressed and disturbed patients. Conclusions: More emphasis needs to be given to the emotional quandaries and concurrent cognitive dissonance experienced by mental health nurses caring for distressed and/or disturbed inpatients in acute psychiatric settings. Increased access to education and training with particular attention to interpersonal communication and relationship building within clinical teams needs to be a priority given the experiences described by mental health nurses.

Keywords: Acute Inpatient Psychiatric Settings; Cognitive Dissonance; Coercive Interventions; Feelings Mental Health Nurse; Thoughts

\section{INTRODUCTION}

Mental health problems are the fastest growing burden for healthcare internationally [1]. Globally, 450 million people suffer from mental health problems with 1 in 4 having experiences of mental health services at some 
point in their life [2]. Of the 7 key areas identified by the WHO European Ministerial Conference on Mental Health (2005) [3], emphasis was given to the promotion of voluntary admission and treatment as the basis of services and involuntary treatment being the exception [4]. Persons treated in psychiatric institutions still experience discrimination and violations of their basic rights due to the stigma associated with mental health problems [5]. These violations tend to be related to the use of coercive interventions [3]. Common forms of coercion used during inpatient treatment include seclusion and mechanical restraints, physical holding, restricted leave and forced psychotropic medication [6-8]. However, such coercive interventions should only be used as a last resort/response. Coercive interventions may be "justified" in a crisis situation that appears to present imminent risk of harm to the patient, staff and/or others [9] to control agitated, aggressive and/or otherwise harmful behaviour $[10,11]$. Persuasion to take medication may be very coercive, even if physical force is not implemented $[6,12]$. Limitations to receiving visitors, denying patients' "vacations" from the ward and restrictions in using the telephone are also forms of coercion frequently seen in psychiatric care $[6,8]$.

The reported rise of patient aggression/hostility in mental health inpatient settings has been of interest to researchers for some time [13-16]. The topic is important as this behaviour can be a major problem in healthcare institutions. It has been estimated that in the UK about $70 \%$ of nurses working in psychiatric institutions have been assaulted at least once during their career [17]. Literature has indicated that patient aggression/hostility may be caused by nurses' high levels of anxiety and/or insecurity $[18,19]$, counter-aggressiveness or a lack of confidence in personal and professional competence [17]. The reactions and coping strategies adopted by mental health nurses are frequently short cuts such as the use of coercive measures or the reduction of contact with the patient $[13,19,20]$.

Gournay (2005) [21] identified that the nature of the nurses' role in acute settings has changed and has become one of the most difficult areas of psychiatry. Coercive practices are complex issues that are ethically challenging because they restrict an individual's autonomy $[22,23]$. There exists a discord between ethical values and the coercive interventions used that can cause problems such as the conflict between caring for and controlling the patients $[6,24,25]$. To control and to help are often interrelated especially in psychiatric settings. The implementation of restrictions includes the risk of misuse of power and perceived punishment, even if the expressed purpose is good $[6,26]$. Nurses may experience negative feelings towards the distressed and/or disturbed patients who have been involved in the use of coercion $[6,18,27]$ and feelings of discomfort can be produced
[28]. In acute environments, staff may not have the necessary clinical skills or time to be able to manage distressed and/or disturbed patients, consequently resorting to other methods of containment. This can generate dissonance for staff as ethically and professionally they wish to avoid using such measures but sometimes have no option. Some nurses have expressed concerns about the unsuccessful search for and use of alternatives to using coercive measures [29].

The feelings and thoughts experienced by mental health nurses when caring for and supporting extremely distressed and/or disturbed patients are not well articulated, yet they would seem to influence the nature and quality of care [13]. In acute clinical environments, patient care and treatment are the responsibilities of the multi-professional team. Mental health nurses feelings and thoughts and duty of care are the responsibilities of the whole team. It has been documented that the feelings and thoughts of a single team member can impact upon the whole team and its internal and external dynamics $[6,30]$.

This paper reports on one element of a European Commissioned Leonardo da Vinci-funded Project: ePsychNurse (F1-06-B-F-PP-160701). The project was concerned with the continuing professional development needs of mental health nurses regarding the care of distressed and/or disturbed patients. Partners from 6 European countries participated: England, Finland, Ireland, Italy, Lithuania and Portugal. Described within the paper are the feelings and thoughts of mental health nurses regarding the care and support of distressed, and/or disturbed patients within acute inpatient settings across six different countries.

\section{METHODS}

\subsection{Setting and Participants}

The settings for the study were acute psychiatric inpatient units in England, Finland, Ireland, Italy, Lithuania and Portugal. All the units were "state-run" and were either part of a general hospital or a larger psychiatric hospital. Six in-patient care organisations participated in the study. Patients within the units were a mixture of detainees and informal admissions.

A purposive sampling frame was used [31]. Mental health nurses who participated were identified by their managers. The inclusion criteria for the study were being a licensed/registered nurse, currently working in an acute in-patient environment with at least one experience of an aggressive event within their work setting. The participants needed to be fluent in the main national language of their country i.e. Finnish, Lithuanian, Portuguese, Italian or English, and be willing to participate in a focus group discussion that would be audiotaped. All partici- 
pants were informed of the nature of the study through written descriptive material and their informed consent was obtained.

In total, 130 mental health nurses participated in 17 focus group interviews in the 6 countries. The number of nurses in each focus group ranged from 6 to 11 . The characteristics of the sample are outlined in Table 1. The majority of nurses were female, which is in line with the general demographic data on nursing [32].The length of participants' working experience varied across the countries with the majority $(\mathrm{n}=57,69 \%)$ having worked in nursing in general between $5-25$ years. The mental health nurses in 5 of the countries all completed their basic education/articulation examination; England data is missing, but we can report that $75 \%$ of mental health nurses in the sample completed similar education.

\subsection{Data Collection}

Focus groups were chosen as the method of data collection offering the opportunity for peer support, exchange of ideas and sharing of common values [33,34]. One of the assumptions underpinning the use of focus groups is that the group dynamic can assist participants to express and clarify their views in ways that are less likely to occur in a one-to-one interview. The group environment may offer a sense of "safety", to those feelings anxious for whatever reason [35]. A data collection protocol was developed to assist with standardization across the countries to help ensure a comparable data collection process [36]. In order to reveal mental health nurses experiences of working with distressed, and/or disturbed patients in the different European countries; guidance questions were formulated based upon expert opinion and a literature review.

A pilot study was undertaken in each of the 6 countries to test the suitability of the questions in terms of wording, content and clinical appropriateness. The outcomes were shared across the partner countries and minor modifications made according to country need. Each focus group was carried out by 2 experienced interviewers. Participants were required to complete a short socio-demographic questionnaire prior to the commencement of the focus group. Each focus group was audio-recorded and had a duration of 1 - 2 hours. Non-verbal communication and the interactions between participants were noted by the interviewers.

\subsection{Ethical Considerations}

Approval to conduct the focus groups was obtained from the appropriate local health authorities and/or research and development committees in each country. Approval from ethics committees was not required as the research did not involve patients. All participants were assured anonymity and confidentiality and informed they could withdraw at any time. Formal written informed consent was obtained from all participants.

\subsection{Data Analysis}

The data from each focus group were transcribed verbatim and content analysed using the technique outlined by Downe-Wamboldt (1992) [37]. This involves the analysis of words, phrases and categories, so that themes can be identified. Participant anonymity and confidentiality were maintained at all times with identifiers. The extraction process involved highlighting any phrase and/or a sentence made by participants that referred to the feelings and thoughts they experienced when caring for and supporting distressed and/or disturbed patients.

In each country the two researchers who conducted the focus groups independently coded the transcript data according to the project protocol for data analysis to ensure homogeneity of procedure. The coded data were then compared and contrasted for agreement and finally reviewed by an independent researcher for verification. Where necessary, all coded data were then translated into English.

\section{RESULTS}

It is apparent from the data that mental health nurses who care for and support distressed and/or disturbed inpatients in acute psychiatric settings experience emotional quandaries and concurrent cognitive dissonance. Cognitive dissonance is the termed coined by Festinger (1956)

Table 1. Characteristics of the sample.

\begin{tabular}{|c|c|c|c|c|c|c|}
\hline $\begin{array}{c}\text { Country } \\
\text { Characteristic }\end{array}$ & England & Finland & Ireland & Italy & Lithuania & Portugal \\
\hline Sample size (n) & 12 & 22 & 23 & 33 & 20 & 20 \\
\hline Male/female & $5 / 7$ & $10 / 12$ & $8 / 15$ & $10 / 23$ & $0 / 20$ & $10 / 10$ \\
\hline No. of focus groups & 3 & 3 & 3 & 4 & 2 & 2 \\
\hline Age in years (majority) & $31-40$ & 44 (mean) & $31-51$ & 40 (mean) & 51 & $31-40$ \\
\hline $\begin{array}{l}\text { Years worked (majority range) (no in } \\
\text { current employment as a mental health nurse }\end{array}$ & $6-15(3)$ & $16-25(11)$ & $1-15(16)$ & $6-15(19)$ & $26(13)$ & $6-15(8)$ \\
\hline
\end{tabular}


[38]. It is the discomfort experienced when simultaneously holding two or more conflicting cognitions: ideas, beliefs, values or emotional reactions. Festinger (1985) [38] states that in a state of dissonance, people may sometimes feel disequilibrium like frustration, hunger, dread, guilt, anger, embarrassment, anxiety. According to Spencer and Myers (2006) [39] cognitive dissonance is the distressing mental state that people feel when they find themselves doing things that don't fit with what they know, or having opinions that do not fit with other opinions they hold.

From the analysed data the following six broad themes were identified:

- Mixed emotions: expressive and responsive

- Procedures for caring for and supporting distressed and/or disturbed patients

- Use of guidelines for caring and supporting disturbed and/or distressed patients

- Team and organisational support

- Ethical concerns: cognitive dissonance

- Education and training.

\subsection{Mixed Emotions: Expressive and Responsive}

Caring for very distressed and disturbed patients evoked strong emotions that were shared across all countries. Fear and anxiety for their own safety, the safety of the individual patient and others were paramount e.g. "It's not nice-the worst part of the job... Fear" (Ireland)..."Fear, anxiety" (Finland).

Most participants highlighted fear of the unknown patient as particularly anxiety provoking e.g. "not sure how they will react" (Italy). This fear was confounded if there was a sense that not all team members were playing an active role in managing the situation, "or were denying their own fears" (Italy). Italian nurses emphasised this more than any other group but all the other countries with the exception of Portugal mentioned it.

Damage to the therapeutic relationship was a further fear especially when resorting to the use of coercive interventions. All groups agreed that such interventions had the potential to negatively impact on the therapeutic relationship but sometimes unavoidable e.g. "Nurses feel that they have failed" (Portugal). "Harms therapeutic relationships so try to avoid it" (England). "A conflicting feeling in the decision to use physical restraint" (Lithuania).

It was acknowledged that in most incidents any initial damage to a relationship is generally "short lived" and maybe more distressing for the nurse than the patient. Some participants were of the opinion that nurses taking control, for example using seclusion is a relief for patients as they don't have to take responsibility for themselves and/or they get "quiet time" something which on busy acute wards may otherwise be denied to them.

A feeling of fear was also generated when nurses had to resort to the use of coercive interventions. The fear experienced here related to physical safety of everyone but it was also associated with the possibility that nurses might loose control and that professional boundaries may be crossed in the heat of the moment e.g. "Lose the self-control in physical or verbal assault, losing the right professional distance" (Italy) "Fear, for the revenge of the patient after restraint, in particular the mechanical one" (Italy), "Traumatic for everyone... Fear and apprehension" (Portugal).

\subsection{Procedures for Caring for and Supporting Distressed and/or Disturbed Patients}

This theme centered around what happens when a disturbed and/or distressed patient is admitted to the unit/ hospital or when an existing patient becomes distressed. There was general agreement across the groups regarding the initial steps necessary to ensure safety and good quality care. The importance of assessing patients' mental health status together with a risk assessement were emphasised by all groups. This would enable staff to determine the best approach to care and some felt it important too in giving an insight into the reason why an individual was distressed e.g. "Try to understand the reasons for the distressed behavior of the patient" (Italy). Throughout emphasis was given to the importance of individual patient care with good communication and observation... "Must always try to embrace the patient" (Portugal). Whether or not staff know the patient an ongoing assessment of his or her risk is important (England).

Common to all groups was the importance of using de-escalating approaches which took a variety of forms. Establishing a good relationship with the patient was considered key with groups suggesting different ways of achieving this e.g. "To co-operate with the patient as much as possible" (Finland), "Using interpersonal relationship... Establishing good rapport" (Ireland)... "Maintain eye contact" (Portugal). Central to the good relationship was speaking with the person in a respectful manner using appropriate language "with cultural sensitivity" (Ireland) and ... "Allowing patients time and opportunity to talk" (England). Staff being non-confrontational and having a friendly face on the ward, someone that the patient knows was viewed as important. The relationship is the primary vehicle of care (Portugal). Being attentive and using a gentle approach were viewed as essential by participants e.g. Care in patient's own room... Co-operation between the wards (Finland), awareness of open space-offering patient room to move around (Ireland). Some nurses also affirmed the importance of the 
ward context:

A second de-escalating approach was "use of the environment" with importance given to calmness, low stimulation, support and being positive. If the atmosphere of the ward is calm and relaxed with friendly personnel there are less aggressive behaviours (Italy). Having nurses visible on the ward was viewed as essential to generating the right environment. Finnish nurses strongly emphasised this point. Further considerations were "Ensuring a low stimulating, calm environment" (Ireland), "Familiar environment and people have a positive effect" (Lithuania). "Positive actions in the situation and establishing a healthy environment" (Portugal). If establishing a healthy, positive environment was not immediately possible then it was considered important to remove the patient to somewhere quiet e.g. "Time out, in own room or other room away from rest of ward" (England).

Portuguese nurses were of the view that "Talking to the patients and the relationship are enough to solve some situations" and Italian nurses considered ... "Direct intervention to pacify the distress pacify the patients and calm them down" was the best approach. Constant observation was viewed as necessary by Finnish nurses and "A good coordination with services is also considered very important to avoid restraint" (Italy).

When all attempts to de-escalate the situation failed and as a last resort coercive interventions had to be used a lot of anxiety and distress was expressed amongst all participants. Some considered it a failure in terms of their clinical skills, team working and professionalism. A range of coercive interventions were used such as physical and mechanical restraint, seclusion and chemical restraint. The views expressed in the groups with regard to physical and mechanical restraint were a fear of hurting the patient and of restricting their freedom e.g. Scared to harm the patient holding him or during a mechanical restriction (Finland). Feel bad because they have the sensation to steal the freedom of the patient (Italy).

Restrains of any form were considered as always unpleasant for everyone with a negative impact on relationships and aprofessional failure e.g. It is always unpleasant restraint the patients... Broke the relationship (Italy).

Guilt was another emotion expressed by the groups. A feeling of guilt and anxiety (Lithuania). English nurses were of the view that physical restrain and seclusion "is more likely to be the outcome if the patient is severely disturbed and psychotic and kicks off without warning".

Finnish and Irish nurses considered medication to be preferable to other forms of restraint. All of the above were considered negative ways of coping with the situation. However, despite the strong emotions surrounding the use of coercive interventions some groups felt that it would be difficult to manage without them e.g. Hard to imagine nursing without physical restraint as a management method (England).

\subsection{Use of Guidelines for Caring and Supporting Disturbed and/or Distressed Patients}

This was one theme where differences across the countries was most marked. With the exception of England none of the countries had national guidelines regarding how to manage distressed and disturbed patients. In the other countries the approach was guided by the organisation, unit policy, the clinical team or individuals. For example, Finnish nurses reported that, "There is no model how to treat aggressive patient or preventive/predictive treatment model-There are only very general rules".

In Italy, Lithuania and Portugalitis the doctors who prescribe the interventions to manage the patient e.g. "The doctor decides the way to manage the patient", "Doctor is usually called by nursing staff during the phase of aggressiveness" (Italy), "Doctor takes the decision" (Lithuania). "There are no guidelines for the management of aggressive and disturbed patients except to restraint a patient it is necessary a doctoral prescription" (Portugal). "Different hospital wards act in different ways in the situation" (Ireland). Italian nurses stated that the "Line of action varies depending on the patient, There are not specific and/or structured guidelines or line of action". "Usually there is a common shared method that comes from experience" (Lithuania).

\subsection{Team and Organisational Support}

Participants were in agreement that both team and organisational support were essential. The nature of that support ranged from having the opportunity to discuss issues informally with colleagues, to the organisation ensuring adequate staffing levels and staff having access to occupational health in the event of an untoward incident.

Discussion with colleagues was viewed as highly important within all countries, for example, Discussion with colleagues..., "Sharing of work experiences..." "Knowledge sharing between colleagues" (Lithiania), "Teamwork, solving the problem of taking care of aggressive patients" (Italy), "It's hard to switch off after an incident" (Ireland), "Informal chats with fellow staff members, often after an incident has occurred" (England). "Colleagues and older staff are the main support" (Portugal). "Departmental meetings" (various problems are discussed there) (Lithuania), "Empowering of potential...", "to have a debate with nurses of other units to discover other and different practices" (Italy).

Organisational support was multifaceted with a gen- 
eral consensus shared across the groups that there was a need for increasing staff-patient ratios to ensure high quality, respectful care and help reduce the number of critical incidents. Increased staffing levels would allow time for debriefing following an incident... Debriefing with staff, though only if there is an opportunity to do so, most often there isn't any time (England)... ...more opportunities for formal debriefings (England). Debriefing, more reflection and discussion on incidents... The medical management of patients from Doctors... (Ireland).

Having sufficient staffing levels on the wards would enable support groups to take place on the wards... Staff support groups on individual wards where any issue can be raised for discussion. Adequate staffing levels together with the right staff skill mix with highly skilled staff on duty at all times was also viewed as an organisational responsibility... More (permanent) staff on duty... More emphasis on multidisciplinary teams (England). More skilled hospital attendants... More support from different services (Lithuania).

Finnish nurses stated that support and report monitoring was essential to ensure nurses were enabled to promote good quality care... Support from the immediate superior (head nurse) and nursing director... Supervision... Monitoring of reports on violence situations (Finland). More support and recognition from managers (England). Irish and Italian nurses were more vociferous regarding the perceived lack of support from both the organisation and clinical teams.

Occupational health support following an incident was viewed as a further organisational responsibility. Not infrequently involvement in critical incidents has an emotional impact on staff and access to occupational health and the support of senior managers is vital. This point was highlighted in particular by English and Finnish nurses... Occupational healthcare following an incident is important (Finland, England).

\subsection{Ethical Concerns: Cognitive Dissonance}

This theme highlights ethical concerns expressed by participants regarding right to liberty and dignity, the protection of the self and others, and internal conflict. The latter refers to the cognitive dissonance experienced by nurses when adopting coercive measures when caring for and supporting disturbed and distressed patients. There were different views expressed across the country groups with some considering coercive measures as having positve elements. A "necessary evil" done with the patient's... It can bring about a good result if it is done in the right, properly controlled way (England). The actions are safe and equitable... The actions are humane. It's in the best interest of the patient (Finland).

Irish nurses were clear that coercion should be avoided if at all possible as it was viewed as, Taking away their dignity and their rights (Ireland). Similarly, with Portuguese nurses. Must always try to embrace the patient... Restraint a patient is not an ethical and deontological behavior (Portugal).

Lithuanian nurses highlighted the dilemmas experienced by nurses... The action is inhumane regarding the patient... A decisional dilemma is presented to the nurses which involve making a choice between risking harm to the patient, the staff and others (Lithuania). Sometimes patients want to be secluded as it gives them personal space (England).

\subsection{Education and Training}

Education and training was viewed as an organisation's responsibility with all participants suggesting the need for appropriate, focused training courses aimed at how to manage distressed and disturbed patients. For some there was no structured training; different models were used.

There is not structured education at the hospital... Each nurse tries to make theoretical course according need. Nurses do not have preparation, only good sense (Italy)... Only a few nurses made theoretical courses, in their services, concerning aggressive patients, restraints methods and communication (Portugal). They learned by themselves and/or supported by the nursing group or by the psychiatrists... Many nurses affirm that their education has been "trial and errors"... continuous education organised by the hospital has always been insufficient regarding the management of the aggressive patient... this has been always very focused on relational aspects or theoretical subjects (Italy).

It was considered essential that the training was targeted specifically to the care of distressed patients with more standardisation across units/hospitals with clear instructions for actions. The theory and training is different to real situations on the ward (England). Poor professional training and lack of experience create uncertainty in the situation (Finland). Can't prepare for the speed of the situation... There are a lot of decisions to be made very quickly... (Finland).

The consensus was that training needed to be more comprehensive and interactive... More role-play in training (England). Some participants wanted courses for nurses only whilst others wanted multi-disciplinary training. Italian nurses were very clear about the latter... Education has to be structured on teamwork in any case, multidisciplinary in character, work in team with the doctors, in a more coordinated and synergic way (Italy).

Other views on the nature of the training were the need for more emphasis on the core skills of nursing; need to include self-awareness and assertiveness elements to build up professional confidence, emphasis on policies and guidelines, ward based practical training with yearly refresher courses. Other suggested curricu- 
lum content included how to communicate with different patient groups; team work; how to analyse situations and events.

\section{DISCUSSION}

The purpose of this study was to describe the feelings and thoughts of mental health nurses regarding the care and support of distressed, and/or disturbed patients within acute inpatient settings across six different countries. Given the themes that emerged from the findings, it seems that restraining patients in whichever way causes both emotional and cognitive issues for nurses. This suggests a concurrent rational and intellectual analysis of experiences rather than simple emotional responses resulting from emotional quandaries.

The uniformity of the answers and shared feelings and thoughts of anxiety and fear expressed by the mental health nurses in the different countries suggests that nurses have common feelings and similar states of dissonance. The nurses try to be ready and open to different management approaches, primarily founded on the therapeutic relationship and its quality in the hope that it will not be affected if difficult interventions ensue. It could be suggested that we are close to the concept of therapeutic pluralism $[40,41]$ that is, the management of the patient according to a plurality of therapeutic options without exclusively following specific guidelines. When caring for and supporting distressed patients the interventions must be based on respect and dignity for the person and always involve the least restrictive options. However, on occasion, physical restraint and/or seclusion may be necessary to ensure both team and patient safety.

Some suppress their emotions in an effort to get through the use of interventions like seclusion and restraint in order to function on a daily basis. There is already literature to support this e.g. emotional distress and emotional suppression as a defence mechanism [18,29, 42-46]. The loss of the therapeutic relationship due to coercive interventions is indicated by Moran et al. (2009) [47]; as the relationship is already broken down nurses continue to use restraint and seclusion techniques and suppress their unpleasant emotions. Furthermore, Morse (2001) [48], states that the emotional suffering of mental health nurses caused by a patient's aggressive behaviour results in their emotional withdrawal from the patient. Moran et al. (2009) [47] conclude that the loss of relationship between nurse and patient may be caused, or at least facilitated, by standardised handlings and the "psychiatrisation" of the patient. Roberts (2005) [49] and Lakeman (2004) [40] state that the quality of the therapeutic relationship is more effective than an accurate choice of intervention strategies [50]. This was also conveyed by some of the mental health nurses in this study.

Although inpatient nurses use coercive interventions, for some it does not present ethical problems [51] as they appear oblivious to practice issues and hold paternalistic attitudes. For some patients seclusion maybe a positive experience as it enables them to have a "quiet" time away from the busy ward environment and an opportunity for reflection.

Support from both peers and managers, was perceived as very important by participant across the 6 countries. The need for infrastructural support that comprised of increasing the staff-patient ratio and having the correct skill mix available was viewed as necessary, as was the importance of smaller, safer and good quality physical environments [52]. Managerial support that included occupational healthcare following an episode of violence or the use of a complex intervention such as seclusion and restrain was considered essential but not always available. Indeed there was a fairly universal view across the countries that senior managers were not always aware or interested in what took place following an incident unless it had repercussions for them personally. The importance of peer and team support including debriefing sessions after an along with supervision from nursing directors were expressed by all participants.

NICE guidelines indicate the importance of debriefing following untoward incidents and consequently included in individual UK Trust policies. No such guidelines exist in the other European countries involved in the study. There is a lack of standardisation across the countries in terms of policies, practices and legislation regarding the management and treatment of disturbed and/or distressed patients. This is left to the discretion of medical staff and senior nurses. Giving the mobility across Europe of both patients and health care professions greater attempts at standardisation should be considered [53].

Regarding educational needs, participants proposed the use of practical education for all nurses at all levels of seniority. They called for continuing education on clinical issues using case-based clinical scenarios and problem based learning. This form of learning can portray effective interactions and support for disturbed and distressed patients similar to that experienced by staff working in mental health inpatient environments who took part in an evaluation of an educational practice development programme [54]. The participants appreciated the knowledge and professional expertise of experienced and older staff to educate and advise them alongside or in addition to individual and teamwork sessions and regular, relevant, structured education and training for all employees was deemed appropriate to encompass ethical and legal issues. Most importantly in this training was the contribution of patients as co-educators [54].

There is a need to research the causes of aggression and its management from the patient's perspective. The outcomes of such research would give nursing staff and 
management more effective tools to potentially predict and prevent this complex and multifactorial phenomenon $[24,55]$. Based on the results of this study we are able to make suggestions for future endeavors. This paper shows that there is still a need to increase availability of education related to patient management and team-working/ support to foster sound internal relationships. We suggest a two-pronged approach: 1) multi-professional education programmes and 2) clinical supervision.

Education is key to changing attitudes and clinical practice $[53,56,57]$. The Mental health nurses in the different countries have described fear and anxiety as prevalent feelings experienced when caring for and supporting distressed and/or disturbed patients as well as support from peers and management. These areas should be included in all multi-professional education organisational programmes for nurses of all levels of seniority. The findings of this study should be taken into consideration in the planning of future educational programs and refresher courses in the updating of Mental health nurses knowledge and skills, and their implications for nursing practice. Such education programmes must incorporate the best available evidence regarding the care and support of distressed and/or disturbed patients from the view of mental health nurses. The core of this education could be based on "real" patient experience/episodes of management when patients are exhibiting aggressive and/or hostile behaviour with shared discussion and points of view from both professional and patient standpoints. In the preparation of standardised clinical guidelines for practice, patients' opinions (voice) should be considered as well as ethical and legal issues; these guidelines should be included in programmes of study for all qualifying and post-qualifying nurses.

Clinical supervision is important in the development of the emotional and intellectual/rational aptitude among 6 nurses $[43,57]$ and may enable them to acknowledge, work through and therefore manage their distressing emotions in a safe and supportive environment [57]. Staff could engage in a process called "dissonance reduction" [58] which can be achieved in one of three ways: 1) lowering the importance of one of the discordant factors, 2) adding consonant elements, 3) or changing one of the dissonant factors. In addition to a professsional education programme a standardised plan of clinical supervision that takes into account the physical environment of the inpatient unit and culture of the country would assist mental health nurses to pause and reflect on the emotional and concurrent cognitive distress they experience when caring for patients.

Managerial support in the form of being visible in clinical areas other than when untoward episodes occur is a further recommendation. Clinical staff need to feel valued and "cared for" when working in such demanding areas. The importance of adequate staffing levels is a prerequisite for safe, effective and compassionate care, consequently a further responsibility of senior managers.

There were a number of limitations in the study. For example, the purposive sampling strategy, small sample size, localisation of the focus groups in each of the 6 countries and the qualitative methodology preclude broad generalisation of the findings. There are also specific limitations of a focus group technique, which may have influenced the findings. For instance, Carey (1994) [59] identifies censoring and conforming as major pitfalls when conducting focus group interviews. These processes occur when a person withholds or alters his/her responses to correspond with the other group members and/or the leader. The processes of conforming and censoring may have potentially influenced the extent of emotional and cognitive distress reported by the mental health nurses in this study. However, there was evidence of this distress within the data from all of the focus group interviews and the data offers useful insights into the feelings and thoughts experienced by mental health nurses when caring for distressed and/or disturbed patients, which will be of interest to the wider mental health nursing community.

Five different languages were employed in the study, and translational and linguistic equivalence difficulties were experienced. Healthcare systems, nurses' education and role, nursing guidelines and/or standards vary therefore the care, treatment and management of distressed and/or disturbed patients who behave aggressively will vary from country to country. Therefore, it is unsurprising that Mental health nurses in different countries have different experiences and different coping strategies to manage such patients. Direct comparisons are therefore difficult.

Despite these limitations, this study draws strength from the inclusion of nurse participants from 6 European countries and the comparison of yielded extensive, rich, in-depth qualitative data about the emotional and cognitive dissonance/distress experienced by these Mental health nurses with regard to the management of distressed and/or disturbed patients. The findings are clearly valuable for future research studies of this kind and for the development of mental health education and practice in all of these countries.

\section{CONCLUSION}

The findings illustrate that the management of this patient group can be a genuine emotional and cognitive distressing experience for the mental health nurses in this study. Through tailored professional education programmes, refresher courses, standardised international guidelines and appropriate clinical supervision, it may be reasonable to assume that mental health nurses may move be- 
yond their distressing emotions and that effective and sound nurse-patient relationships may be nurtured, so that the need for restraint and seclusion interventions will diminish across Europe within mental health nursing.

\section{ACKNOWLEDGEMENTS}

The authors would like to thank the nurses who participated in the study who generously gave their time and partook in the focus group interviews. Thanks also to Carol Hanchard and Veslemoy Guise for their contributions to the research and Vida Staniuliene, Mary Chambers, Maritta Välimäki and Raija Kontio for the first draft of this paper and Vida Staniuliene, Mary Chambers, Anne Scott, Maria Antónia Rebelo Botelho, Renzo Zanott, Maritta Välimäki who obtained the funding.

\section{REFERENCES}

[1] The World Federation for Mental Health (2011) http://www.wfmh.com/2011DOCS/2011\%20WORLD\%2 0MENTAL\%20HEALTH\%20DAY\%20document.pdf

[2] World Health Organization (2001) http://www.who.int/whr/2001/media_centre/press_release len/

[3] WHO European Ministerial Conference on Mental Health (2005).

http://ec.europa.eu/health/mental health/events/ev 20050 112 en.htm accessed 22/07/2013.

[4] World Health Organization (2005) Mental health declaration for Europe. Facing the challenges, building solutions. http://www.euro.who.International/HEN/syntheses

[5] Horsfall, J., Cleary, M. and Hunt, G.E. (2010) Stigma in mental health: Clients and professionals, issues in mental health nursing, 31, 450-455. http://dx.doi.org/10.3109/01612840903537167

[6] Haglund, Von Knorring, L, Von Essen L., et al. (2003) Forced medication in psychiatric care: Patient experiences and nurse perceptions. Journal of Psychiatric and Mental Health Nursing, 10, 65-72.

http://dx.doi.org/10.1046/j.1365-2850.2003.00555.x

[7] Olofsson, B. (2000) Use of coercion in psychiatric care as narratedby patients, nurses and physicians. Dissertation, Umeå University, Umeå.

[8] Välimäki, M., Taipale, J., Kaltiala-Heino, R. (2001) Deprivation of liberty in psychiatric treatment: A Finnish perspective. Nursing Ethics, 8, 522-532.

[9] Kozub, M.L. and Skidmore, R. (2001) Least to most restrictive interventions: A continuum for mental health care facilities. Journal of Psychosocial Nursing, 39, 32-38.

[10] Hopton, J. (1995). The rights and wrongs of control and restraint. Open Mind, 73, 16.

[11] Kaltiala-Heino, R. (1999) Methodological issues in measuring coercion in psychiatric care. In: Morrissey, J.P. and Monahan, J., Eds., Research in Community and Mental Health, JAI Press Inc., Stanford, 123-139.

[12] LeGris, J., Walters, M. and Browne, G. (1999) The impact of seclusion on the treatment outcomes of psychotic in-patients. Journal of Advanced Nursing, 30, 448-459. http://dx.doi.org/10.1046/j.1365-2648.1999.01100.x

[13] Duxbury, J. and Whittington, R. (2005) Causes and management of patient aggression and violence: Staff and patient perspectives. Journal of Advanced Nursing, 50, 469-478.

http://dx.doi.org/10.1111/j.1365-2648.2005.03426.x

[14] Foster, C., Bowers, L. and Nijman H. (2009) Aggressive behaviour on acute psychiatric wards: Prevalence, severity and management. Journal of Advanced Nursing, 58, 140-149. http://dx.doi.org/10.1111/j.1365-2648.2007.04169.x

[15] Rippon, T.J. (2000) Aggression and violence in health care. Journal of Advanced Nursing, 31, 452-460. http://dx.doi.org/10.1046/j.1365-2648.2000.01284.x

[16] Woods, P. and Ashley, C. (2007) Violence and aggression: A literature review. Journal of Psychiatric and Mental Health Nursing, 14, 652-660. http://dx.doi.org/10.1111/j.1365-2850.2007.01149.x

[17] Needham, I., Abderhalden, C., Halfens, R.J.G., et al. (2005) The impact of patient aggression on carers scale: Instrument derivation and psychometrictesting. Scandinavian Journal of Caring Sciences, 19, 296-300. http://dx.doi.org/10.1111/j.1471-6712.2005.00344.x

[18] Bonner, G., Lowe, T., Rawcliffe, D., et al. (2002) Trauma for all: A pilot study of the subjective experience of the physical restraint for mental health inpatients and staff in the UK. Journal of Psychiatric and Mental Health Nursing, 9, 465-473.

http://dx.doi.org/10.1046/j.1365-2850.2002.00504.x

[19] Whittington, R. and Wykes, T. (1994) Going in strong, confrontative coping by staff following assault by a patient. Journal of Forensic Psychiatry, 5, 609-614. http://dx.doi.org/10.1080/09585189408410854

[20] Duxbury, J. (1999) An exploratory account of registerednurses' experience of patient aggression in both mental health and general nursing setting. Journal of Psychiatric and Mental Health Nursing, 6, 107-114. http://dx.doi.org/10.1046/j.1365-2850.1999.620107.x

[21] Gournay, K (2005) The changing face of psychiatric nursing; revisiting mental health nursing. Advances in Psychiatric Treatment, 11, 6-11. http://dx.doi.org/10.1192/apt.11.1.6

[22] Giordano, S. (2000) For the protection of others. Health Care Analysis, 8, 309-319. http://dx.doi.org/10.1023/A:1009404321431

[23] O'Brien, A.J. and Golding, C.G. (2003). Coercion in mental health care: The principle of least coercive care. Journal of Psychiatric and Mental Health Nursing, 10, 167-173. http://dx.doi.org/10.1046/j.1365-2850.2003.00571.x

[24] Camuccio, C.A., Chambers, M., Valimaki, M., Farro, D. and Zanotti, R. (2013) Managing distressed and disturbed patients: The thoughts and feelings experienced by Italian nurses. Journal of Psychiatric and Mental Health Nursing, 19, 807-815. http://dx.doi.org/10.1111/j.1365-2850.2011.01857.x

[25] Thomsen, S, Soares, J, Nolan, P, Dallender, J. and Arnetz, 
B (1999) Feelings of professional fulfillment and exhaustion in mental health personnel: the importance of organizational and individual factors. Psychotherapy and Psychosomatics, 68, 157-164.

http://dx.doi.org/10.1159/000012325

[26] Kaltiala-Heino, R. and Välimäki, M. (2001) Involuntary commitment in health care. European Journal of Health Law, 8, 299-316. http://dx.doi.org/10.1023/A:1015107932705

[27] Eriksson, K.I. and Westrin C.G. (1995) Coercive measures in psychiatric care. Reports and reactions of patients and other people involved. Acta Psychiatrica Scandinavica, 92, 225-230.

http://dx.doi.org/10.1111/j.1600-0447.1995.tb09573.x

[28] Lind, M., Kaltiala-Heino, R., Suominen, T., Leino-Kilpi, H. and Välimäki, M. (2004) Nurses' ethical perceptions about coercion. Journal of Psychiatric and Mental Health Nursing, 11, 379-385.

http://dx.doi.org/10.1111/j.1365-2850.2004.00715.x

[29] Marangos-Frost, S. and Wells, D. (2000) Psychiatric nurses' thoughts and feelings about restrain use: A decision dilemma. Journal of Advanced Nursing, 31, 362369. http://dx.doi.org/10.1046/j.1365-2648.2000.01290.x

[30] Cleary M., Walter, G. and Hunt, G. (2005) The experience and views of mental health nurses regarding nursing care delivery in an integrated, inpatient setting. International Journal of Mental Health Nursing, 14, 72-77.

[31] Streubert-Speziale, H.J. and Carpenter, D.R. (2007) Qualitative research in nursing: Advancing the humanistic imperative. Lippincott Williams \& Wilkins, Philadelphia.

[32] WHO (2009).

http://www.euro.who.int/ data/assets/pdf file/0019/114 157/E93980.pdf

[33] Nachmais, C.F. and Nachmais, D. (2008). Research methods in the Social Sciences. 7th Edition, Worth Publishers, New York.

[34] Savin-Baden, M. and Major, C. (2013) Qualitative research: The essential guide to theory and practice. Routledge, London.

[35] Harding, J. (2013).Qualitative data analysis from start to finish. SAGE, London.

[36] White, M.E., McDonnell, S.M., Werker, D.H., Cardenas, V.M. and Thacker, S.B. (2001) Partnerships in international applied epidemiology training and service, 19752001. American Journal of Epidemiology, 154, 993-999. http://dx.doi.org/10.1093/aje/154.11.993

[37] Downe-Wamboldt, B. (1992) Content analysis: Method, applications, and issues. Health Care for Women International, 13, 313-321. http://dx.doi.org/10.1080/07399339209516006

[38] Festinger, L. (1956) A theory of cognitive dissonance. Stanford University Press, Stanford.

[39] Spencer, D.G. and Myers, S. (2006) Social psychology. 3rd Edition. McGraw-Hill Ryerson, Toronto.

[40] Lakeman, R. (2004) Standardized routine outcome measurement: Pot holes in the road to recovery. International Journal of Mental Health Nursing, 13, 210-215. http://dx.doi.org/10.1111/j.1445-8330.2004.00336.x
[41] Hurley, J., Barret, P. and Reet, P. (2006) "Let a hundred flowers blossom, let a hundred schools of thought contend": A case for therapeutic pluralism in mental health nursing. Journal of Psychiatric and Mental Health Nursing, 13, 173-179.

http://dx.doi.org/10.1111/j.1365-2850.2006.00938.x

[42] Akerjordet, K. and Severinswon, E. (2004) Emotional intelligence in mental health nurses talking about practice. International Journal of Mental Health Nursing, 13, 164170. http://dx.doi.org/10.1111/j.1440-0979.2004.0328.x

[43] Mann, S. \& Cowburn, J. (2005) Emotional labour and stress within mental health nursing. Journal of Psychiatric and Mental Health Nursing, 12, 154-162.

http://dx.doi.org/10.1111/j.1365-2850.2004.00807.x

[44] American Psychiatric Association. (2000) Diagnostic and statistical manual of mental disorders. 4th Edition. American Psychiatric Association, Washington DC.

[45] Pellitteri, J. (2002) The relationship between emotional intelligence and ego defence mechanism. Journal of Psychology, 136, 182-194.

http://dx.doi.org/10.1080/00223980209604149

[46] Crowe, M. (2004) The place of the unconscious in mental health nursing. International Journal of Mental Health Nursing, 13, 2-8. http://dx.doi.org/10.1111/j.1447-0349.2004.00302.x

[47] Moran, A., Cocoman, A., Scott, P.A., et al. (2009) Restrain and seclusion: A distressing treatment option? Journal of Psychiatric and Mental Health Nursing, 16, 599-605.

http://dx.doi.org/10.1111/j.1365-2850.2009.01419.x

[48] Morse, J.M. (2001) Toward a praxis theory of suffering. Advances in Nursing Science, 24, 47-59.

[49] Roberts, M. (2005) The production of the psychiatric subject: Power, knowledge and Michel Foucault. Nursing Philosophy, 6, 33-42.

http://dx.doi.org/10.1111/j.1466-769X.2004.00196.x

[50] Chambers, M. (2005) A concept analysis of therapeutic relationships. In: Cutcliffe, J. and McKenna, H.P., Eds., The Essential Concepts of Nursing, Elsevier, London, 301-316.

[51] Lind, M., Kaltiala-Heino, R., Suominen, T., Leino-Kilpi, H. and Välimäki, M. (2004) Nurses' ethical perceptions about coercion. Journal of Psychiatric and Mental Health Nursing, 11, 379-385.

http://dx.doi.org/10.1111/j.1365-2850.2004.00715.x

[52] Foster, C., Bowers, L. and Nijman, H. (2007) Aggressive behaviour on acute psychiatric wards: Prevalence, severity and management. Journal of Advanced Nursing, 58, 140-149.

http://dx.doi.org/10.1111/j.1365-2648.2007.04169.x

[53] Chambers, M., Guise, V., Valimaki, M., Botelho, M.A., Scott, A., Staniuliene, V. and Zanotti, R. (2010) Nurses' attitudes to mental illness: A comparison of a sample of nurses from five European countries. International Journal of Nursing Studies, 47, 350-362. http://dx.doi.org/10.1016/j.ijnurstu.2009.08.008

[54] Chambers, M., Gillard, S., Turner, K. and Borschmann, R. (2013) Evaluation of an educational practice development 
programme for staff working in mental health inpatient environments. Journal of Psychiatric and Mental Health Nursing, 20, 362-373. http://dx.doi.org/10.1111/j.1365-2850.2012.01964.x

[55] Marinopoulos, S.S., Dorman, T., Ratanawongsa, N., Wilson, L.M., Ashar, B.H., Magaziner, J.L., Miller, R.G., Thomas, P.A., Prokopowicz, G.P., Qayyum, R. and Bass, E.B. (2007) Effectiveness of continuing medical education, evidence reports/technology assessments. Agency for Healthcare Research and Quality (US) Report No. 07E006, Rockville.

[56] Gardner, H. (1983) Frames of mind. Basic Books, New
York.

[57] Goleman, D. (1998) Working with emotional intelligence. Bantam Books, New York.

[58] Festinger, L. (1956) Psychology: The science of behaveiour. 4th Edition. Pearson, Toronto.

[59] Carey, A. (1994) The group effect in focus groups: Planning, implementing and interpreting focus group research. In: Morse, J. M., Ed., Critical Issues in Qualitative Research Methods, Sage Publications, Thousand Oaks, pp. 225-241. 